\title{
Unusual sex differences in tuberculosis notifications across Pakistan and the role of environmental factors
}

\author{
M.S. Khan, ${ }^{1}$ M.S. Khan, ${ }^{2}$ R. Hasan ${ }^{2}$ and P. Godfrey-Faussett ${ }^{1}$
}

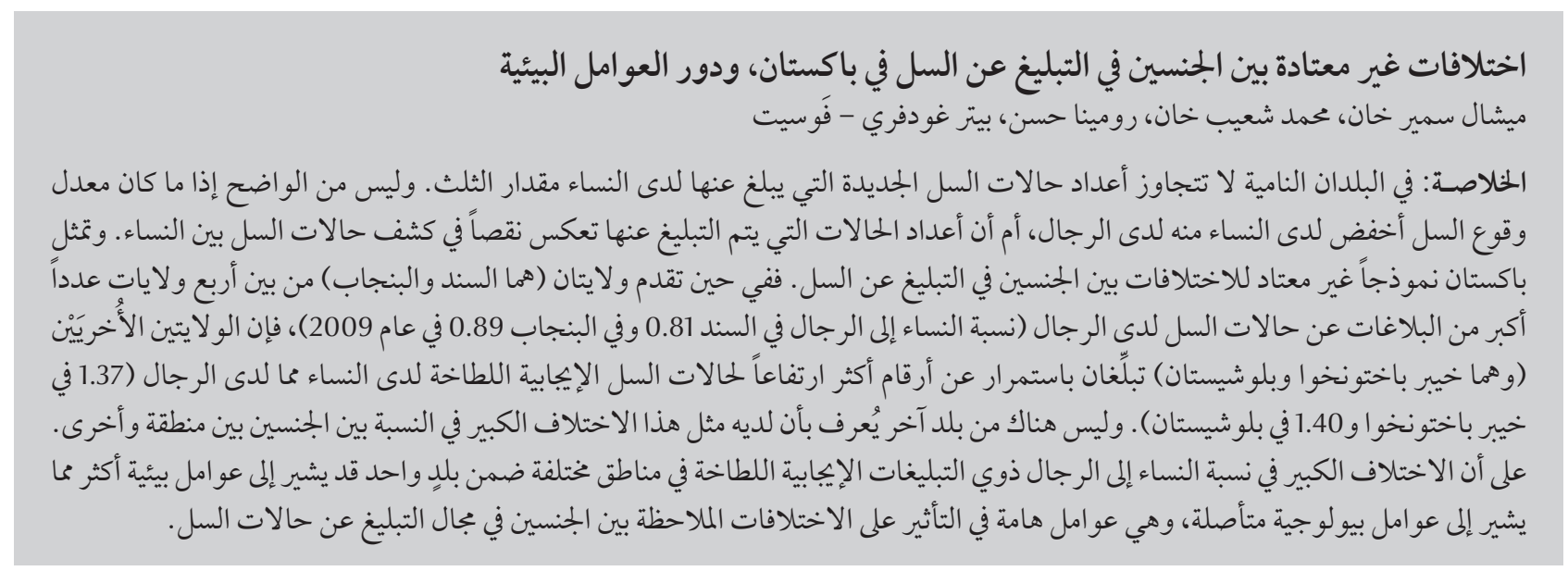

ABSTRACT In developing countries, only one-third of new tuberculosis cases notified are from women. It is not clear whether tuberculosis incidence is lower in women than men, or whether notification figures reflect under-detection of tuberculosis in women. Pakistan, however, presents an unusual pattern of sex differences in tuberculosis notifications. While 2 of the 4 provinces (Sindh and Punjab) report more notifications from men (female to male ratios 0.81 and 0.89 respectively in 2009), the other 2 provinces (Khyber-Pakhtunkhwa and Balochistan) consistently report higher numbers of smear-positive tuberculosis notifications from women than men (1.37 and 1.40). No other country is known to have such a large variation in the sex ratios of notifications across regions. Large variations in female to male smear-positive notification ratios in different settings across a single country may indicate that environmental factors, rather than endogenous biological factors, are important in influencing the observed sex differences in tuberculosis notifications.

Différences inhabituelles liées au sexe dans les notifications de cas de tuberculose sur l'ensemble du territoire pakistanais et rôle des facteurs environnementaux

RÉSUMÉ Dans les pays en développement, seul un tiers des nouveaux cas de tuberculose notifiés concerne des femmes. On ne sait pas si l'incidence de la tuberculose est plus faible chez les femmes que chez les hommes ou si les chiffres des notifications reflètent un dépistage insuffisant de la tuberculose chez ces dernières. Toutefois, le Pakistan présente une répartition inhabituelle des notifications de cas de tuberculose entre les deux sexes. Si deux provinces sur quatre (le Sindh et le Pendjab) transmettent un plus grand nombre de notifications concernant des hommes (rapport femme-homme de 0,81 et 0,89 en 2009 dans chaque province respectivement), en revanche les deux autres provinces (le Khyber-Pakhtunkhwa et le Baloutchistan) transmettent de manière permanente des chiffres de notifications de cas de tuberculose à frottis positif plus élevés chez les femmes que chez les hommes (rapport femme-homme de 1,37 et 1,40 dans chaque province respectivement). Aucun autre pays n'est connu pour présenter une telle différence entre les sexes dans les notifications entre les régions. De grandes différences dans les chiffres de notifications de tuberculose à frottis positif entre les hommes et les femmes dans des environnements différents sur l'ensemble d'un territoire national peuvent être le signe que des facteurs environnementaux, plutôt que des facteurs biologiques endogènes, pèsent sur les différences observées entre les deux sexes pour les notifications de cas de tuberculose. 


Sex differences
in tuberculosis
notifications

The topic of sex differences in tuberculosis (TB) notifications generates considerable debate, be it among academics, doctors or fieldworkers. It is well documented that in most regions of the world more adult men are diagnosed with and die from $\mathrm{TB}$ than women $[1,2]$. Because of this, the impact of $\mathrm{TB}$ on women is often underestimated, and TB is perceived to be a disease that affects men more than women. The World Health Organization (WHO) estimates that there were 9.4 million new cases of TB globally in 2009. Based on the observed sex difference in notifications, it is estimated that women would account for $35 \%$ of all cases [3]. However, since reasons for lower TB notification among women are poorly understood, it is not clear whether TB incidence is lower in women than men, or whether notification figures reflect under-detection of $\mathrm{TB}$ in women.

Broadly, there are 4 categories of explanations for the sex differences in case notifications:

- variations in levels of exposure to TB $[2,4]$;

- immunological and physiological factors leading to differences in susceptibility to developing disease post-exposure $[5,6]$;

- discrepancies in access to health care for diagnosis and treatment $[7,8]$;

- differences in the probability of being correctly diagnosed by existing health-systems [9].

The first 2 explanations suggest a true difference in the incidence of disease between men and women, whereas the second 2 suggest that the observed sex difference is due to cases being selectively missed in women.
Prevalence surveys, by eliminating barriers to access to health centres, are assumed to provide an answer to whether more men or women in the population have TB; but even these may not provide a gender-neutral assessment of TB. For instance, prevalence surveys usually do an initial screen of the population looking for symptoms suggestive of TB (prolonged cough, sputum expectoration and haemoptysis), all of which are reported to be less common among female TB patients than males [10]. They also use a similar protocol for diagnosing smear-positive TB as do most diagnostic centres, i.e. smearmicroscopy without gender-sensitive sputum submission instructions. The use of smear-microscopy has been shown to selectively under-diagnose smear-positive TB in women unless good sputum submission instructions and a private space for expectoration are provided [9]. If women with TB have atypical symptoms or find it difficult to expectorate good sputum specimens, this will introduce a gender bias in smear-positive case detection at diagnostic centres and in prevalence surveys.

It remains unclear not only which of the 4 categories of explanation contribute most to observed sex differences in TB notifications but also whether environmental or endogenous factors are more important determinants of the sex difference. "Endogenous factors" are intrinsic biological differences that occur in individuals owing to their sex, and are less likely to vary across different settings. Their influence would result in true differences in the incidence of TB. "Environmental factors" is a broad term encompassing the social, economic, geographical and infrastructural characteristics of an individual's surroundings. It includes living conditions and health-service quality. Environmental factors can influence sex differences in exposure to $\mathrm{TB}$ infection or sex differences in immunological and physiological development that affect the risk of disease post-infection. This would lead to true differences in disease incidence between men and women. Environmental factors can also influence access to diagnosis for men and women, leading to a bias in the diagnosis or reporting of TB between the sexes.

Much of the debate therefore has focussed on whether sex differences in notifications are "real" or "observed". This may not be the most important point though. It may be more useful from an intervention planning point of view to understand the extent to which environmental factors contribute to observed sex differences in $\mathrm{TB}$ notifications. If environmental rather than endogenous factors are largely responsible for the sex differences (in incidence or diagnosis of TB), it would mean that interventions to address these environmental factors will be useful and necessary to address the discrepancy between sexes.

\section{The case of Pakistan}

The unusual pattern of TB notifications across Pakistan raises questions about the role of environmental factors influencing sex differences in TB. Pakistan has a population of approximately 175 million [11] with a female to male ratio (F:M) in the population of $0.9: 1$. The country is subdivided into 4 provinces as well as some federally administered areas. KhyberPakhtunkhwa (formerly North-West Frontier province) and Balochistan provinces are in the western part of the country bordering Afghanistan and Islamic Republic of Iran, while Sindh and Punjab provinces are in the eastern part bordering India (Figure 1). The latest census indicated that the population ratios of females to males in Khyber-Pakhtunkhwa, Balochistan, Sindh and Punjab were $0.95,0.87,0.93$ and 0.89 respectively 
[11]. Unlike sub-Saharan Africa, where a higher prevalence of human immunodeficiency virus (HIV) in women affects sex differences in TB incidence, the prevalence of HIV in Pakistan is low. Pakistan is therefore one of the few countries in which sex differences in TB can be studied with minimal influence of the HIV epidemic [12].

Although the vast majority of developing countries report fewer TB cases from women, Pakistan presents an unusual pattern of sex differences in TB notifications. Of the 4 provinces, Khyber-Pakhtunkhwa and Balochistan consistently report higher smear-positive TB notifications from women than men, and Punjab and Sindh report higher smear-positive notifications from men (Table 1 ). This pattern of sex differences in notifications is consistent across several years of data. Interestingly, the sex difference between provinces is most pronounced for smear-positive cases. An analysis of new notifications of all form of TB in 2007 (Table 2), showed that compared with smear-negative and extra-pulmonary $\mathrm{TB}$, the difference in F:M notification ratios between provinces is most pronounced for smearpositive TB.

Apart from the present analysis of TB notifications, a South Asian Association for Regional Cooperation study of sex differences in 7 countries also highlighted Pakistan as being the only one to have more cases diagnosed in women than men. This was due to a higher number of female than male TB suspects undergoing sputum examination in the national TB control programme (NTP) centres included in the study in Pakistan (F:M ratio 1.2), but not in the other countries. The proportion of male and female suspects testing smear-positive in Pakistan was very similar (approximately 17\%), leading to an overall higher number of female smear-positive cases being detected in the centres sampled in $\mathrm{Pa}$ kistan [13].

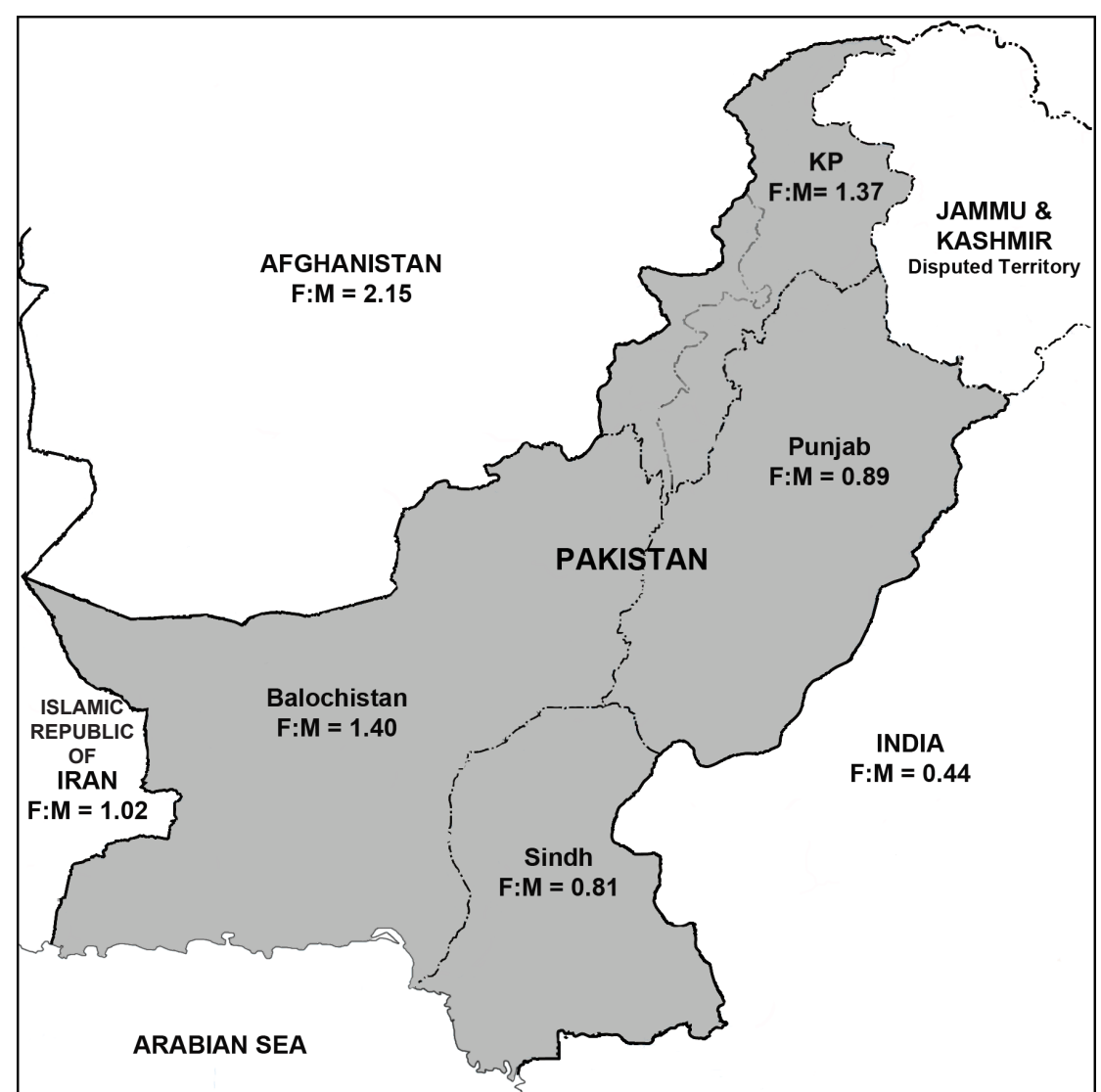

Figure 1 Map showing the 4 provinces of Pakistan and its neighbouring countries with their respective female to male ratios (F:M) of smear-positive tuberculosis notifications

A particularly interesting observation is that Sindh and Punjab provinces have similar F:M notification ratios to India, which they share a border with. Khyber-Pakhtunkhwa and Balochistan, the 2 provinces which have more TB notifications from females than males, border Islamic Republic of Iran and Afghanistan, which also report higher notifications from females than males. These are among very few developing countries that diagnose more TB cases in females. Khyber-Pakhtunkhwa and Balochistan are the least socioeconomically developed provinces and are considered the most conservative as far as women's education, travel and empowerment are concerned. It is therefore surprising to those working in TB control that these provinces, as well as Afghanistan, report more cases from women than men. Lower mobility and access to health services of women would be consistent with fewer, not more, notifications from women than men in these areas. Of course factors such as the use of private sector health-care providers that do not report TB cases to the NTP and migration of men out of some regions in search of employment may also play a role; unfortunately information on this is poorly documented.

A recent review on sex inequalities in TB proposes that biological sex-related factors such as sex steroid hormones, the genetic makeup of the sex chromosomes and sex-specific metabolic features may play an important role in making women more resistant to $M y$ cobacterium tuberculosis than men [14]. However, endogenous factors intrinsic to men and women would be expected to act across the whole of Pakistan, if not across men and women in all settings. It should therefore be considered that 


\begin{tabular}{|c|c|c|c|}
\hline \multirow[t]{2}{*}{ Year/province } & \multicolumn{2}{|c|}{ No. of cases } & \multirow[t]{2}{*}{ F:M ratio } \\
\hline & Females & Males & \\
\hline \multicolumn{4}{|l|}{2006} \\
\hline Sindh & 8153 & 10646 & 0.77 \\
\hline Punjab & 13788 & 15947 & 0.86 \\
\hline Khyber-Pakhtunkhwa & 5844 & 4278 & 1.37 \\
\hline Balochistan & 1978 & 1367 & 1.45 \\
\hline \multicolumn{4}{|l|}{2007} \\
\hline Sindh & 9585 & 12006 & 0.80 \\
\hline Punjab & 22459 & 25331 & 0.89 \\
\hline Khyber-Pakhtunkhwa & 6844 & 5030 & 1.36 \\
\hline Balochistan & 2094 & 1564 & 1.34 \\
\hline \multicolumn{4}{|l|}{2008} \\
\hline Sindh & 9848 & 12099 & 0.81 \\
\hline Punjab & 27558 & 30370 & 0.91 \\
\hline Khyber-Pakhtunkhwa & 7110 & 5232 & 1.36 \\
\hline Balochistan & 2040 & 1519 & 1.34 \\
\hline \multicolumn{4}{|l|}{2009} \\
\hline Sindh & 7734 & 9539 & 0.81 \\
\hline Punjab & 27963 & 31249 & 0.89 \\
\hline Khyber-Pakhtunkhwa & 7572 & 5547 & 1.37 \\
\hline Balochistan & 1938 & 1384 & 1.40 \\
\hline
\end{tabular}

$F: M=$ female to male.

large variations in F:M smear-positive notification ratios in different settings across a single country may indicate that environmental factors are important in influencing the observed sex differences in TB notifications. For example, the only study looking at sex differences in diagnostic centres across Pakistan found that health centre characteristics such as accessibility by foot had a significant effect on the number of female suspects registered [15].

Determinants of sex differences in $\mathrm{TB}$ notifications in the Eastern
Mediterranean Region, and in other settings with higher TB notifications from women than men have not been thoroughly studied as yet. Environmental factors that may be influencing the observed provincial differences in $\mathrm{TB}$ sex ratios across Pakistan include differences in poverty levels, climate, sociocultural practices, smoking and use of private health providers between the 4 provinces. For example, indicators of poverty such as household wealth, fertility and literacy indicate that Balochistan and Khyber-Pakhtunkhwa, which have higher notifications from women than men, are also the poorer provinces.

\section{Conclusions}

The unusual case of Pakistan highlights the fact that we still have a long way to go in understanding sex differences in TB notifications and reasons for them. The perception that women are less likely to have TB than men should be challenged as it could turn out to be a self-fulfilling prophecy. Looking at previous years' notification figures, those working in TB control tend to assume that fewer women have TB than men. Planners of TB control strategies and physicians screening $\mathrm{TB}$ suspects may then consciously or subconsciously put more emphasis on detecting TB in men and less attention on interventions to improve case detection among women. At the end of the year, more cases of TB may be detected in men than women, reinforcing the original perception. It is therefore important to keep the debate alive on this topic, particularly in the light of data from high TB-burden countries such as Pakistan and Afghanistan. Hypotheses about potentially important environmental factors influencing the observed sex differences in TB notifications need to be tested, and it is hoped that this paper will initiate interest in studying this topic.

\section{Acknowledgements}

Funding: None.

Competing interest: None declared.

\begin{tabular}{|c|c|c|c|c|}
\hline \multirow[t]{2}{*}{ Province } & \multicolumn{4}{|c|}{ F:M ratio } \\
\hline & All new cases & Smear +ve cases & Smear-ve cases & Extrapulmonary cases \\
\hline Sindh & 0.93 & 0.80 & 1.00 & 1.33 \\
\hline Punjab & 0.98 & 0.89 & 1.01 & 1.19 \\
\hline Khyber-Pakhtunkhwa & 1.32 & 1.36 & 1.33 & 1.24 \\
\hline Balochistan & 1.34 & 1.34 & 1.38 & 1.24 \\
\hline
\end{tabular}




\section{References}

1. Howson CP et al. In her lifetime: female morbidity and mortality in sub-Saharan Africa. Washington DC, National Academy Press, 1996.

2. Gender and tuberculosis. Gender and Health Research Series. Geneva, World Health Organization, 2004.

3. Global tuberculosis control 2010. Geneva, World Health Organization, 2010.

4. Holmes $C B$, Hausler $H$, Nunn P. A review of sex differences in the epidemiology of tuberculosis. International Journal of Tuberculosis and Lung Disease, 1998, 2(2):96-104.

5. Dolin P. Tuberculosis epidemiology from a gender perspective. In: Diwan V, Thorson A, Winkvist A, eds. Gender and tuberculosis. Göteborg, Sweden, Nordic School of Public Health, 1998.

6. Radhakrishna S, Frieden TR, Subramani R. Association of initial tuberculin sensitivity, age and sex with the incidence of tuberculosis in south India: a 15-year follow-up. International Journal of Tuberculosis and Lung Disease, 2003, 7(11):10831091.

7. Cassels A et al. Tuberculosis case-finding in Eastern Nepal. Tubercle, 1982, 63(3):175-185.

8. Needham DM et al. Socio-economic, gender and health services factors affecting diagnostic delay for tuberculosis patients in urban Zambia. Tropical Medicine and International Health, 2001, 6(4):256-259.
9. Khan MS et al. Improvement of tuberculosis case detection and reduction of discrepancies between men and women by simple sputum-submission instructions: a pragmatic randomised controlled trial. Lancet, 2007, 369:1955-1960.

10. Long NH, Diwan VK, Winkvist A. Difference in symptoms suggesting pulmonary tuberculosis among men and women. Journal of Clinical Epidemiology, 2002, 55(2):115-120.

11. Pakistan Census Organization. Islamabad, Government of Pakistan, 2011 (http://www.census.gov.pk/, accessed 9 July 2013).

12. Global report. UNAIDS report on the global AIDS epidemic 2010. Geneva, Joint United Nations Programme on HIV/AIDS, 2010.

13. Gender differences among TB patients in national TB control programmes within SAARC countries. Kathmandu, Nepal, South Asian Association for Regional Cooperation TB Centre, 2004.

14. Neyrolles O, Quintana-Murci L. Sexual inequality in tuberculosis. PLoS Med, 2009, 6(12):e1000199.

15. Khan MS et al. Factors influencing sex differences in numbers of tuberculosis suspects at diagnostic centres in Pakistan. International Journal of Tuberculosis and Lung Disease, 2012, 16:172-177. 